\title{
HEMATOLOGIC AND SERUM CHEMISTRY VALUES OF THE CAPTIVE EUROPEAN WILDCAT
}

\author{
Ignasi Marco, ${ }^{1,3,4}$ Fernando Martinez, ${ }^{2}$ Josep Pastor, ${ }^{3}$ and Santiago Lavin ${ }^{1,3}$ \\ 1 Servicio de Ecopatología de Fauna Salvaje, Facultad de Veterinaria, Universidad Autonoma de Barcelona, \\ 08193-Bellaterra, SPAIN \\ 2 Zoovet, Serveis Veterinaris per a Fauna Exotica i Salvatge, Apt. Correus 99006, 08080-Barcelona, SPAIN \\ ${ }^{3}$ Patologia General y Medica, Facultad de Veterinaria, Universidad Autonoma de Barcelona, 08193-Bellaterra, SPAIN \\ ${ }^{4}$ Corresponding author (e-mail: Ignasi.Marco@uab.es).
}

ABSTRACT: Hematologic and serum chemistry values were determined for 20 adult captive E uropean wildcats (Felis silvestris) in Lleida (Catalonia, Spain). Seven wildcats (4 females and 3 males) were captured in the wild and 13 (4 females and 9 males) were born and raised in captivity. Samples were collected between September and December from 1993 to 1998. Blood was obtained by jugular venipuncture after administration of either ketamine and xylazine or ketamine and medetomidine. Females had significantly higher mean eosinophil counts, albumin concentration, (and A/G ratio) and lower mature neutrophil counts, although these differences were not clinically relevant. Results for many of the blood parameters fall within the reference range for domestic cats. M ean values for alanine aminotransferase, aspartate aminotransferase, creatine phosphokinase, and lactate dehydrogenase activities as well as blood urea nitrogen, glucose, and sodium concentrations were higher than the upper limit of the reference range for domestic cats.

Key words: E uropean wildcat, F elis silvestris, hematology, serum chemistry reference values.

\section{INTRODUCTION}

The E uropean wildcat (Felis silvestris) populated forestland areas throughout E urope, with numbers declining in the 18th and 19th centuries as a result of deforestation, habitat loss, shooting, and trapping for fur, and persecution for attacks on livestock and gamebirds. In some areas populations have recovered due to an increased availability of favourable habitats and a decrease in persecution, but there are still numerous threats, including accidental and deliberate killing, diseases, toxic chemicals, and hybridization with domestic cats (M cOrist et al., 1991; M cO rist and Kitchener, 1994).

Baseline characteristics of hematologic and serum biochemical parameters have not been published for the E uropean wildcat, and comparisons are usually made with data obtained from the domestic cat. The objectives of this study were to determine hematologic and serum chemistry reference values for this species. Reference intervals would be useful for evaluation of physiological and pathological alterations in wild and captive wildcat individuals and populations.

\section{MATERIALS AND METHODS}

Blood samples were collected from 20 adult untamed European wildcats (12 males and 8 females), aged between 1 and 9 yr. The seven older wildcats (4 females and 3 males) were captured in the wild in the Catalonian Pyrenees region of northeastern Spain $\left(42^{\circ} 14^{\prime} \mathrm{N}\right.$ to $42^{\circ} 49^{\prime} \mathrm{N}, 0^{\circ} 44^{\prime} \mathrm{E}$ to $1^{\circ} 19^{\prime} \mathrm{E}$ ). They were used to establish a captive colony at the Wildlife Rescue Center of Vallcalent (Lleida, Spain; $41^{\circ} 38^{\prime} \mathrm{N}, 0^{\circ} 35^{\prime} \mathrm{E}$ ) for breeding and reintroduction in areas where extinction has occurred, and have spent at least $3 \mathrm{yr}$ in captivity. The remaining 13 animals ( 4 females and 9 males) were born and raised in captivity. The wildcats were housed outdoors in $3 \times 3 \times 3 \mathrm{~m}$ cages in ambient light and temperature. They were fed a mixed ration containing whole chicken, quail, and rabbit. Water was provided ad libitum. All the animals were fasted for $12 \mathrm{hr}$ before blood samples were drawn. Samples were collected primarily between September and December from 1993 to 1998.

For sample collection, the wildcats were anesthetized within a restraint cage using either a mixture of xylazine (Rompun ${ }^{\circledR}$, B ayer, L everkusen, Germany) and ketamine (I malgene $1000^{\circledR}$, R hone $M$ erieux, Lyon, $\mathrm{F}$ rance) or medetomidine (D omtor ${ }^{\circledR}$, O rion, Espoo, F inland) and ketamine. The dosages used were calculated on the estimated body weight of each animal. The xylazine-ketamine doses used were $1.5-3 \mathrm{mg} / \mathrm{kg}$ and $12-15 \mathrm{mg} / \mathrm{kg}$ respectively, and the medetomidine-ketamine doses were $80 \mu \mathrm{g} /$ 
$\mathrm{kg}$ and $2.5-7.5 \mathrm{mg} / \mathrm{kg}$ respectively, administered intramuscularly with a hand-held syringe. The induction time was between 5 and 10 min and blood samples were taken immediately thereafter. Additional doses were not needed in any case.

Animals were examined for clinical signs of disease and temperature, pulse and respiration were monitored. No animal died during or after blood sampling. Only blood data from apparently healthy wildcats were included in this study. Blood samples were obtained from the jugular vein, using disposable syringes and 23 gauge needles. One $\mathrm{ml}$ of blood was placed into tubes containing EDTA $K_{3}$ anticoagulant, with the remainder being placed into a non-anticoagulant tube. Blood in the non-anticoagulant tube was left to clot at room temperature for 1 $\mathrm{hr}$. It was then centrifuged at 2,500 rpm for 10 min, the serum was removed and kept at $4 \mathrm{C}$ until arrival at the laboratory, where it was stored at $-20 \mathrm{C}$ until analysis.

Red blood cell count (RBC), packed cell volume (PCV), hemoglobin concentration ( $\mathrm{Hb}$ ), mean corpuscular volume (MCV), mean corpuscular hemoglobin ( $\mathrm{MCH}$ ), mean corpuscular hemoglobin concentration $(\mathrm{MCHC})$, and white blood cell count (WBC) were measured using a semi-automated hematology analyzer (Sysmex F-800, Toa M edical E lectronics, $\mathrm{H}$ amburg, Germany), adapted to work with animal blood by adjusting the two mobile volume discriminators, one low and one high. PCV was also measured, by centrifuging blood for $5 \mathrm{~min}$ in a microhematocrit tube using a hematocrit centrifuge ( $\mathrm{M}$ icro- $\mathrm{H}$ aematocrit Centrifuge, $\mathrm{H}$ awksley, UK), in order to adjust the values obtained with the analyzer. Differential leukocyte counts were made from blood smears stained with a commercial Wright's stain (Q uick Panoptic, Química Aplicada, Amposta, Spain), using 1000X magnification. A total of 100 leukocytes were examined per slide.

Biochemical analysis was performed using a Kovas Bio autoanalyzer (Roche, Nutley, $\mathrm{N}$ ew Jersey, USA) at 37 C. Activities of alanine aminotransferase (ALT), aspartate aminotransferase (AST), creatine phosphokinase (CK), gamma glutamyltransferase (GGT) and lactate dehydrogenase (LDH), and concentrations of triglycerides, cholesterol, blood urea nitrogen $(B \cup N)$, total bilirubin, creatinine, glucose, sodium, potassium, and chloride were measured. Total serum protein concentration (TP) was determined by the Biuret method, using a 4010 photometer (Boheringer $\mathrm{M}$ anheim, $\mathrm{H}$ amburg, Germany). To differentiate protein fractions, serum protein electrophoresis was performed on cellulose acetate membranes in a high resolution buffer at $250 \mathrm{~V}$ for $30 \mathrm{~min}$. M embranes were then stained and cleared before reading in a photodensitometer (D igiscan Atom 434, Biotron Scientific Instruments, Barcelona, Spain).

Statistical analysis was performed with statistics software (SPSS-PC, SPSS I nc., Chicago, IIlinois, USA). A Kolmogorov-Smirnov test was used to assess a normal distribution of the parameters. A Lilliefors table was used for interpretation of D max of the Kolmogorov-Smirnov test. The effects of animal sex on the various blood parameters were determined using a one-way ANOVA test. The minimum significance value chosen was $P \leq 0.05$.

\section{RESULTS}

The results for the hematologic and 22 serum chemistry parameters are given in Tables 1 and 2, respectively. The parameters followed a normal distribution according to Kolmogorov-Smirnov test and Lilliefors table. There were some significant differences in hematologic and serum chemistry parameters between sexes. Compared to males, females had a significantly $(P<0.05)$ higher mean $( \pm S D)$ eosinophil count $\left(2.17 \pm 1.25 \times 10^{3} / \mu\right)$ versus $\left.1.00 \pm 0.80 \times 10^{3} / \mu \mathrm{l}\right)$, albumin (3.83 $\pm 0.47 \mathrm{~g} / \mathrm{dl}$ versus $3.21 \pm 0.57 \mathrm{~g} / \mathrm{dl}$ ) and $\mathrm{A} / \mathrm{G}$ ratio (1.04 \pm 0.29 versus $0.76 \pm 0.24)$ and a lower mature neutrophil count (7.17 $\pm 2.32 \times 10^{3} / \mu$ l versus $9.49 \pm 3.63 \times 10^{3} /$ $\mu l)$.

\section{DISCUSSION}

Results of hematologic parameters were generally similar to published domestic cat values (Bush, 1991; Jain, 1993). In wildcats, however, slightly higher values were observed in numbers of RBC, WBC, neutrophils and eosinophils and $\mathrm{MCH}$ concentration, and slightly lower values for MCV. Some of these differences may be of physiological origin, such as excitement and struggling during restraint. Acute stress is known to increase RBC, WBC and neutrophil counts in domestic cats. The increase in neutrophil numbers is specially pronounced in the cat because the mean marginal pool in clinically normal cats is about three times greater than the circulating pool (Jain, 1993). In other wild 
TABLE 1. Hematological parameters from 20 captive E uropean wildcats.

\begin{tabular}{llccc}
\hline \multicolumn{1}{c}{ M easurement } & $\mathrm{n}$ & M ean (SD ) & Range & $\begin{array}{c}\text { Normal range for } \\
\text { domestic cats }^{\mathrm{b}}\end{array}$ \\
\hline Red blood cells $\left(\times 10^{6} / \mu \mathrm{l}\right)$ & 20 & $9.38(1.21)$ & $7.85-11.41$ & $5-10$ \\
Packed cell volume $(\%)$ & 20 & $37.7(3.6)$ & $31-46$ & $30-45$ \\
Hemoglobin $(\mathrm{g} / \mathrm{dl})$ & 20 & $12.1(1.3)$ & $9.6-14.9$ & $8-15$ \\
M CV (fl) & 20 & $40.4(2.9)$ & $34.7-47.7$ & $39-55$ \\
M CH (pg) & 20 & $13.0(1.1)$ & $10.8-14.6$ & $12.5-17.5$ \\
M CH C $(\mathrm{g} / \mathrm{dl})$ & 20 & $32.2(1.4)$ & $30.0-34.9$ & $30-36$ \\
White blood cells $\left(\times 10^{3} / \mu \mathrm{l}\right)$ & 20 & $14.67(4.07)$ & $9.20-26.10$ & $5.5-19.5$ \\
N eutrophils $\left(\times 10^{3} / \mu \mathrm{l}\right)$ & 20 & $8.65(3.31)$ & $3.68-14.88$ & $2.5-12.5$ \\
N eutrophil banding $\left(\times 10^{3} / \mu \mathrm{l}\right)$ & 20 & $0.13(0.17)$ & 0.52 & $0-0.3$ \\
Lymphocytes $\left(\times 10^{3} / \mu \mathrm{l}\right)$ & 20 & $4.12(1.55)$ & $1.82-7.35$ & $1.5-7.0$ \\
M onocytes $\left(\times 10^{3} / \mu \mathrm{l}\right)$ & 20 & $0.39(0.29)$ & $0.11-0.99$ & $0.1-0.85$ \\
E osinophils $\left(\times 10^{3} / \mu \mathrm{l}\right)$ & 20 & $1.47(1.14)$ & $0.29-3.68$ & $0.1-1.5$ \\
Basophils $\left(\times 10^{3} / \mu \mathrm{l}\right)$ & 20 & 0 & 0 & Rare \\
\hline
\end{tabular}

a $($ SD $)=$ Standard deviation.

b F rom Bush (1991) and Jain (1993).

felids, a similar leukocytosis and neutrophilia have been recorded and attributed to capture stress (Fuller et al., 1985; Kocan et al., 1985; Weaver and Johnson, 1995). L eukocyte numbers, however, usually demonstrate the greatest variations when comparing different studies within the same species (H eidt et al., 1988).

The higher range of eosinophils in the wildcats of our study, compared with domestic cats and other wild felids (Fuller et al., 1985; Jain, 1993; Weaver and Johnson,

TABLE 2. Biochemical parameters from 20 captive E uropean wildcats.

\begin{tabular}{|c|c|c|c|c|}
\hline M easurement & $\mathrm{n}$ & M ean $(S D)^{a}$ & Range & $\begin{array}{l}\text { Normal range for } \\
\text { domestic cats }\end{array}$ \\
\hline Total protein $(\mathrm{d} / \mathrm{dl})$ & 20 & $7.74(0.49)$ & $7.0-8.8$ & $5.0-8.0$ \\
\hline Albumin (g/dl) & 18 & $3.49(0.60)$ & $2.12-4.27$ & $2.5-4.0$ \\
\hline Alpha-1 globulins (g/dl) & 18 & $0.35(0.11)$ & $0.20-0.62$ & $0.2-1.1$ \\
\hline Alpha-2 globulins (g/dl) & 18 & $0.82(0.33)$ & $0.40-1.13$ & $0.4-0.92$ \\
\hline Beta-1 globulins (g/dl) & 18 & $0.32(0.12)$ & $0.16-0.61$ & $0.3-0.9$ \\
\hline Beta-2 globulins (g/dl) & 18 & $0.51(0.17)$ & $0.34-1.08$ & $0.4-1.0$ \\
\hline Gamma globulins (g/dl) & 18 & $2.20(0.79)$ & $1.01-3.77$ & $1.5-3.5$ \\
\hline Albumin : globulin & 18 & $0.88(0.29)$ & $0.39-1.48$ & $0.4-1.3$ \\
\hline $\operatorname{ALT}(\mathrm{U} / \mathrm{I})$ & 18 & $55.8(20.8)$ & $22.0-94.2$ & $6-83$ \\
\hline AST (U/I) & 18 & $46.2(14.0)$ & $23-74.0$ & $26-43$ \\
\hline CK (U/I) & 18 & $304.4(154.2)$ & $58-623$ & $7.2-28.2$ \\
\hline GGT (U/I) & 18 & $2.03(1.41)$ & $0.50-5.0$ & $1.3-5.1$ \\
\hline LDH (U/I) & 18 & $452.8(305.2)$ & $20.4-1,236$ & $63-273$ \\
\hline Triglycerides (mg/dl) & 18 & $46.35(26.34)$ & $14.3-106.0$ & $50-100$ \\
\hline Cholesterol (mg/dl) & 18 & $111.1(36.8)$ & $43.0-193.0$ & $75-250$ \\
\hline BUN (mg/dl) & 18 & $38.0(12.7)$ & $15.4-57.3$ & $20-30$ \\
\hline Total bilirubin (mg/dl) & 18 & $0.09(0.09)$ & $0-0.33$ & $0.12-0.3$ \\
\hline Creatinine (mg/dl) & 18 & $1.30(0.29)$ & $0.77-1.72$ & $0.5-1.5$ \\
\hline Glucose (mg/dl) & 9 & $167(66)$ & $101-316$ & $60-100$ \\
\hline Sodium (mE q/l) & 14 & $166.7(6.11)$ & $156-172$ & $145-157$ \\
\hline Potassium (mE q/l) & 14 & $5.21(0.28)$ & $4.7-5.6$ & $3.6-5.5$ \\
\hline Chloride $(\mathrm{mE} \mathrm{q} / \mathrm{l})$ & 9 & $123.6(4.01)$ & $118.8-130.2$ & $115-130$ \\
\hline
\end{tabular}

$\mathrm{a}(\mathrm{SD})=$ Standard deviation.

b F rom Bush (1991). 
1995; D unbar et al., 1997), could be related to parasitism and physiological stress (Jain, 1993). It is unlikely that endoparasitism is the cause because animals were checked and treated for endoparasites periodically. In addition, it was noted that individual wildcats with the highest neutrophil count also had the highest eosinophil count, supporting a role of physiological stress.

M ost serum biochemical parameters were similar to reported reference values for domestic cat (Bush, 1991; Kaneko, 1997), but several differences were observed. Some of these are difficult to explain and could be related to individual variation. High activities of muscle enzymes have been described in other species of wild felids due to strenuous exercise, struggling before handling and muscle damage from trapping, darting and anesthetic injection. Values for AST and ALT from wild caught Iberian lynx (Lynx pardina) (Beltran et al., 1991) and bobcats (Lynx rufus) (Fuller et al., 1995) were higher than those recorded for captive $\mathrm{Ca}$ nadian lynx (L ynx canadensis) (Weaver and Johnson, 1995). Activities of AST, CK and LDH were slightly increased in wild mountain lions (F elis concolor) compared to captive ones (Currier and Russell, 1982). Thus, the increases in muscle enzymes (ALT, AST, CK, LDH) in the cats of our study, are attributed to the stress of physical capture in a restraint cage.

The higher mean value for BUN in the wildcats compared to the domestic cat was not associated with higher mean values for creatinine. $\mathrm{H}$ igher $\mathrm{BUN}$ values were not seen in the oldest cats and cannot be attributed to renal dysfunction in older cats, as has been reported in Canadian lynx (Weaver and Johnson, 1995). BUN values also are influenced by diet. The diet of wildcats probably has a higher protein content than that of domestic cat, which would explain the higher BUN. This discrepancy has been reported in other felid species (Currier and Russell, 1982; Fuller et al., 1985).
Glucose concentrations increase in cats with excitement and stress, and with drugs, like ketamine and xylazine, which were used for immobilizing the wildcats in our study. In domestic cats, stress associated with the collection of a blood sample (particulary if struggling occurs), can increase glucose values to greater than 300$400 \mathrm{mg} / \mathrm{dl}$. Xylazine can raise glucose levels more than $500 \%$ (Bush, 1991). In the wildcats, the mean value of glucose was higher than the upper limit of the reference range of domestic cats, with some animals having glucose values greater than $300 \mathrm{mg} / \mathrm{dl}$. These values are similar to those published for captive and wild caught felids (Currier and Russell, 1982; Heidt et al., 1988; Fuller et al., 1995; Weaver and Jonson, 1995; D unbar et al., 1997).

In cats on a high protein diet, excessive fluid loss due to a marked urea-induced diuresis can cause an increase in sodium values (Bush, 1991). This could have occurred in the wildcats of our study and correlates with the increased values of BUN. H owever, in other wild felids fed a similar high protein diet, BUN values are within the normal range for the domestic cat (Currier and Russell, 1982; Fuller et al., 1995; Weaver and Jonson, 1995; D unbar et al., 1997).

These data provide reference values for healthy adult captive European wildcats and can serve as a useful baseline for both captive and wild animals. The animals were handled with drugs, and immobilization techniques similar to those in most field studies. We believe that a single reference range can be used for hematologic and serum chemistry data for both male and female wildcats, because the differences found seem to be of little clinical value, as in the domestic cat (Jain, 1993). The deviation of some wildcat blood values from the normal range for domestic cat were likely the result of capture stress and/or nutritional status. H owever, minor variations in results sometimes may merely represent a different test methodology. 
These aspects should be considered to better assess and evaluate the health status of individuals and populations of wildcats.

\section{ACKNOWLEDGMENTS}

The authors express their sincere appreciation to X. M arco, C. Piñol, D. Sanchez and V. $U$ gidos, from the Wildlife Rescue Center of Vallcalent in Lleida, for their cooperation in facilitating this study.

\section{LITERATURE CITED}

Beltran, J. F., M. Delibes, F. Recio, and C. Aza. 1991. H ematological and serum chemical characteristics of the iberian Iynx (Lynx pardina) in southwestern Spain Canadian Journal of Zoology 69: 840-846.

BUSH, B. M. 1991. Interpretation of laboratory results for small animal clinicians. Blackwell Scientific Publications, Oxford, UK, $515 \mathrm{pp}$.

Currier, M. J. P., AND K. R. RusSell. 1982. Hematology and blood chemistry of the mountain Iion (Felis concolor). J ournal of Wildlife D iseases 18: 99-104.

DUNBAR, M. R., P. NOL, AND S. B. LINDA. 1997. $\mathrm{H}$ ematologic and serum biochemical reference intervals for F lorida panthers. J ournal of Wildlife Diseases 33: 783-789.

FULLER, T. K., K. D. KERR, AND P. D. KARNS. 1985. $\mathrm{H}$ ematologic and serum chemistry of bobcats in north central $M$ innesota. Journal of Wildlife $D$ iseases 21: 29-32.

HEIDT, G. A., R. A. RuCKER, M. L. KENNEDY, AND M. E. BAEYENS. 1988. Hematology, intestinal parasites, and selected disease antibodies from a population of bobcats ( $F$ elis rufus) in Central Arkansas. J ournal of Wildlife D iseases 24: 180-183.

J AIN, N . C. 1993. E ssentials in veterinary hematology. L ea \& F ebiger, Philadelphia, Pennsylvannia, 417 pp.

KANEKo, J., J. W. HARVEY, AND M. L. BRuss. 1997. Clinical biochemistry of domestic animals. 5th E dition. Academic Press, London, UK, 932 pp.

KOCAN, A. A., E. F. BLOUIN, AND B. L. GUNN. 1985. $\mathrm{H}$ ematologic and serum chemical values for freeranging bobcats, F elis rufus (Schreber), with reference to animals with natural infections of $\mathrm{Cy}$ tauxzoon felis Kier, 1979. Journal of Wildlife D iseases 21: 190-192.

MCORIST, S., R. BOID, T. W. JONES, N. EASTERbeE, A. L. HubBARD, AND O. JaRRET. 1991. Some viral and protozoal diseases in the E uropean Wildcat (Felis silvestris). Journal of Wildlife D iseases 27: 693-696.

, AND A. C. KITCHENER. 1994. Current threats to the E uropean Wildcat, F elis silvestris, in Scotland. Ambio 23: 243-245.

WEAVER, J. L., AND R. JOHNSON. 1995. Hematologic and serum chemistry values of captive canadian Iynx. J ournal of Wildlife D iseases 31: 212-215.

Received for publication 29 July 1999. 